\title{
The flow Confluence of river systems of the Pskem and Koksu river basins
}

\author{
Farrukh Shaazizov* \\ Tashkent institute of irrigation and agricultural mechanization engineers, Tashkent, Uzbekistan
}

\begin{abstract}
In the Bostanlyk district of the Tashkent region, there are highmountain breakthrough lakes located in the Pskem and Koksu rivers basin, which pose a particular danger to the downstream territories. The river system of the basins of the Pskem and Koksu rivers located in the Tashkent region is characterized by the presence of many nodes of a confluence of tributaries that form the hydrographic network of the basins of the highmountain rivers under consideration. In the event of man-made and natural emergencies, a breakthrough wave can form on high-mountain outbursthazardous lakes. The main purpose of these studies is to develop a method for the hydraulic calculation to determine the depths of flows in the confluence nodes. Based on the use of the law of conservation of momentum, a model and method for calculating the junction of open water streams have been developed. To determine the depth $h_{2}$ in the main channel after the confluence point, we recommend using the well-known hydraulic methods for determining the depth of water in open channels. Determination of the depths $h_{1}$ and $h_{0}$ of the main flow and inflow, respectively, can be analytically obtained based on the obtained dependences (9) and (10).
\end{abstract}

\section{Introduction}

It should be noted that at present, there is the most intensive development for construction and cultivation of crops in the coastal zones of high-mountain rivers, which are susceptible to flooding when the high-mountain lakes and reservoirs located above them burst, in particular, in the Bostanlyk district of the Tashkent region.

The Gosarkhitektstroy and the Ministry of Emergency Situations have shown a certain interest in determining flooding zones, calculating the main hydraulic parameters for the passage of a breakthrough wave, which can be formed when the dams of upstream highmountainous lakes and reservoirs break through, to determine the zones of safe urban planning and make the most effective architectural and planning decisions in populated areas.

The river system of the basins of the Pskem and Koksu rivers located in the Tashkent region is characterized by the presence of many nodes of the confluence of tributaries, which form the hydrographic network of the basins of the considered high-mountain rivers.

* Corresponding author: shosfarruh@mail.ru 
A characteristic feature of these nodes is that there is a flow in them with a change in flow rate along the path, and channel deformations occur in the form of erosion and silting. To determine the flooding zones during the breakthrough of high-mountain lakes, it is necessary to consider all the above phenomena and find out the nature of the change in the flow depth at the confluence nodes [6-27].

The main purpose of these studies is to develop a method for the hydraulic calculation to determine the depths of flows in the confluence nodes.

\section{Methods}

With the passage of flood discharges along the river, the water flow regime along the river can be assumed to be conditionally established. For this regime of movement of the water flow, a simpler solution can be obtained.

Based on these considerations, let us consider the case of steady motion, the solution of which can be obtained in a more explicit form.

Consider the case of joining flows in prismatic rectangular channels at an angle $\varphi \leq 90^{\circ}$ (Figure.1).

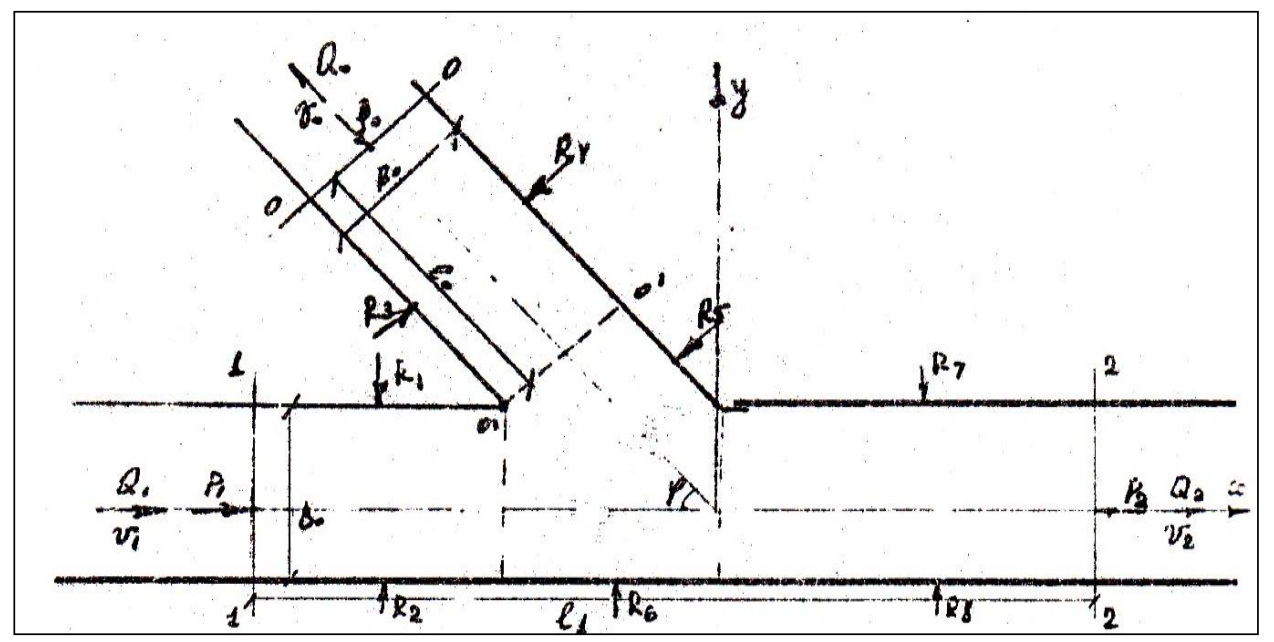

Fig. 1. Analytical model union stream

According to the studies carried out by many authors, the depth $h_{2}$ is established in the channel after the confluence, which is determined only by the flow regime available here. With a relatively large length of the channel passing the total flow, the depth $h_{2}$ can be determined using the Shezy formula, and when an uneven, planned, smoothly changing movement is established in the main channel, it is necessary to know the conditions that determine this movement to determine $h_{2}$.

Therefore, to determine the depth $h_{2}$ in the main channel, one can use the well-known hydraulic methods to determine water depth in open channels. As for the question of determining the depths $h_{l}$ and $h_{0}$ of the main flow and inflow, respectively, analytically can be obtained based on the law of conservation of momentum for a system of material points. According to the law of change in the momentum for the calculation scheme shown in Figure 1, we compose the following equations:

- In projection on the $\mathrm{OX}$ axis 


$$
\Delta C M_{X}=\left(C M_{1}+C M_{0} \cos \varphi\right) \Delta t=\sum F_{X} \Delta t
$$

- In projection on the OY axis

$$
\Delta C M_{Y}=C M_{0} \cos \varphi \Delta t=\sum F_{X} \Delta t
$$

The left-hand sides of equations (1) and (2) are respectively:

- In projection on the OX axis

$$
\alpha_{0} \rho\left(Q_{2} V_{2}-Q_{1} V_{1}-Q_{0} V_{0} \cos \varphi\right) \Delta t
$$

- In projection on the OY axis

$$
-\alpha_{0} \rho Q_{0} V_{0} \sin \varphi \Delta t
$$

The right-hand sides of Eqs. (1) and (2) include the projections of the impulses of forces acting on a dedicated fluid compartment bounded by sections 1-1, 2-2, and $0-0$. These forces include:

- Forces of hydrodynamic pressure in the above sections;

- $\quad$ Forces of reactions of side walls;

- $\quad$ Gravity of the allocated fluid compartment;

- $\quad$ Friction forces.

1. The sum of the projections of the hydrodynamic pressure forces will be:

- In projection on the OX axis

$$
\sum P_{X}=P_{1}-P_{2}+P_{0} \cos \varphi=\rho g \frac{B h_{1}^{2}}{2}-\rho g \frac{B h_{2}^{2}}{2}+\rho g \frac{B h_{0}^{2}}{2} \cos \varphi
$$

- In projection on the OY axis

$$
\sum P_{Y}=-P_{0} \sin \varphi=-\rho g \frac{B_{0} h_{0}^{2}}{2} \sin \varphi
$$

2. The sum of the projections of the reaction forces of the side walls, given that the reaction forces $R_{1}$ and $R_{2}, R_{3}$ and $R_{4}, R_{7}$ and $R_{8}$ are equal in magnitude and opposite in direction, will be

- In projection on the OX axis

$$
\sum R_{X}=-R_{5} \sin \varphi=-\rho g B_{0}\left(\frac{h_{0}+h_{2}}{2}\right)^{2} \frac{\cos \varphi}{2}
$$


- In projection on the $\mathrm{OY}$ axis

$$
\sum R_{Y}=-R_{6}-R_{5} \sin \varphi=-\frac{\rho g B_{0}\left(\frac{h_{0}+h_{2}}{2}\right)^{2}}{2 \sin \varphi}-\frac{\rho g B_{0}\left(\frac{h_{0}+h_{2}}{2}\right)^{2} \operatorname{ctg} \varphi \cos \varphi}{2}
$$

3. The sum of the projections of gravity will be:

- In projection on the OX axis

$$
\sum G_{X}=G_{1}+G_{0} \cos \varphi=\rho g B\left(h_{1}+h_{2}\right) i l_{1} / 2+\rho g\left(B_{0} h_{0} l_{0} i_{0}+B_{0}^{2} h_{0} i_{0} c t g / 2\right) \cos \varphi
$$

- In projection on the OY axis

$$
\sum G_{Y}=-G_{0} \sin \varphi=-\rho g\left(B_{0} h_{0} l_{0} i_{0}+B_{0}^{2} h_{0} i_{0} c t g / 2\right) \sin \varphi
$$

4. We neglect the projections of friction forces due to their smallness.

Substituting the values of the parameters included in equation (1) and making some transformations we have:

$$
\begin{aligned}
& \frac{\alpha_{0}}{g}\left(\frac{Q_{2}^{2}}{B h_{2}}-\frac{Q_{1}^{2}}{B h_{1}}-\frac{Q_{0}^{2} \cos \varphi}{B_{0} h_{0}}\right)=\frac{B h_{1}^{2}}{2}-\frac{B h_{2}^{2}}{2}+\frac{B_{0} h_{0}^{2}}{2} \cos \varphi-\frac{B_{0} \cos \varphi}{2}\left(\frac{h_{0}+h_{2}}{2}\right)^{2}+ \\
& +B i l_{1} \frac{h_{1}+h_{2}}{2}+B_{0} h_{0} i_{0} \cos \varphi\left(\frac{l_{0}+B_{0} \operatorname{ctg} \varphi}{2}\right)
\end{aligned}
$$

Substituting the values of the parameters included in equation (2) and making some transformations we have:

$$
\begin{aligned}
& \frac{\alpha_{0}}{g}\left(\frac{Q_{0}^{2} \sin \varphi}{B_{0} h_{0}}\right)=\frac{B_{0} h_{0}^{2}}{2} \sin \varphi+\frac{B_{0} \operatorname{ctg} \varphi \cos \varphi}{2}\left(\frac{h_{0}+h_{2}}{2}\right)^{2}-\frac{B_{0}}{2 \sin \varphi}\left(\frac{h_{1}+h_{2}}{2}\right)^{2}+ \\
& +B_{0} h_{0} i_{0} l_{0} \sin \varphi+\frac{B_{0}^{2} h_{0} i_{0} \cos \varphi}{2}
\end{aligned}
$$

\section{Results and discussion}

The results of comparisons of the experimental data of other authors and the data obtained on the basis of calculations based on dependencies (9) and (10) show their good convergence.

As calculations show, the relative error when comparing the results obtained on the basis of the obtained dependences with the data of other authors is from +1.8 to $-3.4 \%$.

In this regard, the obtained calculated dependences (9) and (10) are proposed for determining the depths of the water flow in front of the division unit, both in the main channel and in the channel of the inflow. 


\section{Conclusions}

1. Based on the law of conservation of momentum, a model and methodology for calculating the junction of open water streams have been developed.

2. To determine the depth $h_{2}$ in the main channel after the confluence point, we recommend using the well-known hydraulic methods for determining the depth of water in open channels.

3. Determination of the depths $h_{l}$ and $h_{0}$ of the main stream and inflow, respectively, can be analytically obtained on the basis of the obtained dependences (9) and (10).

4. The results of comparisons of the experimental data of other authors and the data obtained on the basis of calculations based on dependencies (9) and (10) show their good convergence. As calculations show, the relative error when comparing the results obtained on the basis of the obtained dependences with the data of other authors is from +1.8 to $-3.4 \%$.

Table 1. Comparison of theoretical results with experimental data of G.A. Petrov

\begin{tabular}{|c|c|c|c|c|c|c|c|c|c|c|}
\hline \multirow{4}{*}{ \# } & \multicolumn{3}{|c|}{$\begin{array}{c}\text { Water discharge, } \\
1 / \mathrm{s}\end{array}$} & \multicolumn{5}{|c|}{ Depth, mm } & \multirow{3}{*}{\multicolumn{2}{|c|}{$\begin{array}{l}\text { Relative } \\
\text { error,\% }\end{array}$}} \\
\hline & \multirow{3}{*}{$Q_{l}$} & \multirow{3}{*}{$Q_{2}$} & \multirow{3}{*}{$Q_{0}$} & \multicolumn{3}{|c|}{ main stream } & \multirow{2}{*}{\multicolumn{2}{|c|}{ Inflow, $h_{0}$}} & & \\
\hline & & & & \multirow{2}{*}{$\begin{array}{c}\text { after } \\
\text { mergers, } h_{2}\end{array}$} & \multicolumn{2}{|c|}{ before the merger, $h_{l}$} & & & & \\
\hline & & & & & experience & theor. & experience & theor. & $\varepsilon \mathrm{h}_{1}$ & $\varepsilon \mathrm{h}_{0}$ \\
\hline 1 & 25.0 & 31.9 & 6.9 & 180 & 194 & 196.9 & 209 & 208.3 & -1.49 & +0.3 \\
\hline 2 & 20.5 & 30.4 & 9.9 & 168 & 188 & 192.3 & 209 & 206.3 & -2.2 & +1.3 \\
\hline 3 & 15.6 & 21.1 & 5.5 & 146 & 158 & 163 & 175 & 171.9 & -3.4 & +1.8 \\
\hline 4 & 21.5 & 27 & 5.5 & 154 & 168 & 170.3 & 182 & 177.2 & -1.3 & +1.8 \\
\hline 5 & 20.5 & 28.3 & 7.8 & 170 & 187 & 190.5 & 201 & 203.2 & -1.8 & -1.1 \\
\hline 6 & 11.4 & 21.1 & 9.7 & 144 & 156 & 159.4 & 178 & 183.2 & -2.2 & -2.9 \\
\hline
\end{tabular}

\section{References}

1. F. Shaazizov, A. Badalov, A. Ergashev, and D. Shukurov, "Studies of rational methods of water selection in water intake areas of hydroelectric power plants," in E3S Web of Conferences, 2019, vol. 97, doi: 10.1051/e3sconf/20199705041.

2. F. Shaazizov and D. Shukurov, "Physical modeling of the filtration process through the dam base," in IOP Conference Series: Materials Science and Engineering, 2020, vol. 869, no. 7, doi: 10.1088/1757-899X/869/7/072037.

3. F. Shaazizov, A. Badalov, D. Shukurov, and D. Yulchiev, "Hydraulic elevator for cleaning sediment of a water outlet of a reservoir," in IOP Conference Series: Materials Science and Engineering, 2020, vol. 883, no. 1, doi: 10.1088/1757899X/883/1/012018.

4. D. Bazarov, F. Shaazizov, and S. Erjigitov, "Transfer of Amudarya flowing part to increase the supportability of the Uzbekistan southern regions," in IOP Conference Series: Materials Science and Engineering, 2020, vol. 883, no. 1, doi: 10.1088/1757899X/883/1/012068.

5. F. Shaazizov, B. Uralov, E. Shukurov, and A. Nasrulin, "Development of the computerized decision-making support system for the prevention and revealing of dangerous zones of flooding," in E3S Web of Conferences, 2019, doi: 10.1051/e3sconf/20199705040.

6. O. Birjukova, S. Guillen, F. Alegria, and A. H. Cardoso, "Three dimensional flow field at confluent fixed-bed open channels," in Proceedings of the International Conference on Fluvial Hydraulics, RIVER FLOW 2014, 2014, pp. 1007-1014, doi: 10.1201/b17133-136. 
7. S. U. S. H. A. N. T. K. Biswal, p. R. A. N. A. B. Mohapatra, and K. Muralidhar, "Hydraulics of combining flow in a right-angled compound open channel junction," Sadhana - Acad. Proc. Eng. Sci., vol. 41, no. 1, pp. 97-110, 2016, doi: 10.1007/s12046-015-0442-y.

8. G. Bombar and A. H. Cardoso, "Effect of the sediment discharge on the equilibrium bed morphology of movable bed open-channel confluences," Geomorphology, vol. 367, 2020, doi: 10.1016/j.geomorph.2020.107329.

9. K. M. Buzby and R. C. Viadero Jr., "Structural and functional aspects of treated mine water and aquaculture effluent streams," Hydrobiologia, vol. 583, no. 1, pp. 251-263, 2007, doi: 10.1007/s10750-006-0534-0.

10. K. Chen, M. Feng, T. Zhang, and S. Teng, "Study on distribution of pollutant concentrations in intersection of open channel Shuili Fadian Xuebao/Journal Hydroelectr. Eng., vol. 38, no. 10, pp. 86-100, 2019, doi: 10.11660/slfdxb.20191008.

11. S. Creëlle, L. Schindfessel, P. X. Ramos, and T. De Mulder, "Experimental investigation of the flow evolution in the tributary of a $90^{\circ}$ open channel confluence," in River Flow - Proceedings of the International Conference on Fluvial Hydraulics, RIVER FLOW 2016, 2016, pp. 1667-1673, doi: 10.1201/9781315644479-260.

12. J. Holden, M. Gascoign, and N. R. Bosanko, "Erosion and natural revegetation associated with surface land drains in upland peatlands," Earth Surf. Process. Landforms, vol. 32, no. 10, pp. 1547-1557, 2007, doi: 10.1002/esp.1476.

13. D. V. Kozlov and A. A. Ghebrehiwot, "Efficacy of digital elevation and Nash models in runoff forecast," Mag. Civ. Eng., vol. 87, no. 3, pp. 103-122, 2019, doi: 10.18720/MCE.87.9.

14. Q. W. Lewis and B. L. Rhoads, "LSPIV Measurements of Two-Dimensional Flow Structure in Streams Using Small Unmanned Aerial Systems: 2. Hydrodynamic Mapping at River Confluences," Water Resour. Res., vol. 54, no. 10, pp. 7981-7999, 2018, doi: 10.1029/2018WR022551.

15. T.-H. Liu, W. Guo, and L. Zhan, "Experimental study of the velocity profile at $90^{\circ}$ open channel confluence," Shuikexue Jinzhan/Advances Water Sci., vol. 20, no. 4, pp. 485-489, (2009)

16. H. Luo, D. K. Fytanidis, A. R. Schmidt, and M. H. García, "Comparative 1D and 3D numerical investigation of open-channel junction flows and energy losses," $A d v$. Water Resour., vol. 117, pp. 120-139, 2018, doi: 10.1016/j.advwatres.(2018.05.012)

17. T. Nagai, A. Tandon, H. Yamazaki, and M. J. Doubell, "Evidence of enhanced turbulent dissipation in the frontogenetic Kuroshio Front thermocline," Geophys. Res. Lett., vol. 36, no. 12, 2009, doi: 10.1029/2009GL038832.

18. L. Schindfessel, S. Creëlle, T. Boelens, and T. De Mulder, "Flow patterns in an open channel confluence with a small ratio of main channel to tributary discharge," in Proceedings of the International Conference on Fluvial Hydraulics, RIVER FLOW 2014, 2014, pp. 989-996, doi: 10.1201/b17133-134.

19. L. Schindfessel, S. Creëlle, and T. De Mulder, "Dynamic mode decomposition applied to the shear layer flows in an open channel confluence," in River Flow - Proceedings of the International Conference on Fluvial Hydraulics, RIVER FLOW 2016, 2016, pp. 1674-1682, doi: 10.1201/9781315644479-261.

20. A. Shakibaeinia, Y. B. Dibike, S. Kashyap, T. D. Prowse, and I. G. Droppo, “A numerical framework for modelling sediment and chemical constituents transport in the Lower Athabasca River," J. Soils Sediments, vol. 17, no. 4, pp. 1140-1159, 2017, doi: 10.1007/s11368-016-1601-4.

21. L. M. Stahr and E. D. Loucks, "Flood control solutions for Bayou Henderson, Ascension Parish, LA," in World Environmental and Water Resources Congress 2008: Ahupua'a - Proceedings of the World Environmental and Water Resources 
Congress 2008, 2008, vol. 316, doi: 10.1061/40976(316)587.

22. J. Todd Petty, J. L. Hansbarger, B. M. Huntsman, and P. M. Mazik, "Brook trout movement in response to temperature, flow, and thermal refugia within a complex Appalachian riverscape," Trans. Am. Fish. Soc., vol. 141, no. 4, pp. 1060-1073, 2012, doi: 10.1080/00028487.2012.681102.

23. H. Wang, B. Wang, X. Liu, X. Wang, and T. Liu, "Experimental study on water-level fluctuation characteristics at open channel confluence zone," Sichuan Daxue Xuebao (Gongcheng Kexue Ban)/Journal Sichuan Univ. (Engineering Sci. Ed., vol. 47, pp. 13-17, 2015, doi: 10.15961/j.jsuese.(2015.s1.003)

24. X. Wang, X. Yan, H. Duan, X. Liu, and E. Huang, "Experimental study on the influence of river flow confluences on the open channel stage-discharge relationship," Hydrol. Sci. J., vol. 64, no. 16, pp. 2025-2039, (2019), doi: 10.1080/02626667.2019.1661415.

25. Q. Y. Yang, T. H. Liu, W. Z. Lu, and X. K. Wang, "Numerical simulation of confluence flow in open channel with dynamic meshes techniques," Adv. Mech. Eng., vol. 2013, 2013, doi: 10.1155/2013/860431.

26. E. Kan, M. Mukhammadiev, N. Ikramov, and T. Majidov, "Full-scale testing of the pump unit with a frequency converter," in IOP Conference Series: Materials Science and Engineering, 2020, vol. 883, no. 1, doi: 10.1088/1757-899X/883/1/012112.

27. N. Ikramov, T. Majidov, E. Kan, and A. Mukhammadjonov, "Monitoring system for electricity consumption at pumping stations," in IOP Conference Series: Materials Science and Engineering, 2020, vol. 883, no. 1, doi: 10.1088/1757899X/883/1/012101. 